\title{
Effects of short-term fasting on in vivo rumen microbiota and in vitro rumen fermentation characteristics
}

\author{
Jong Nam Kim ${ }^{1,2}$, Jaeyong Song ${ }^{3}$, Eun Joong $\mathrm{Kim}^{3}$, Jongsoo Chang ${ }^{4}$, Chang-Hyun Kim ${ }^{5}$, \\ Seongwon Seo ${ }^{1}$, Moon Baek Chang ${ }^{6}$, and Gui-Seck Bae ${ }^{6, *}$
}

\author{
* Corresponding Author: Gui-Seck Bae \\ Tel: +82-31-670-3029, Fax: +82-31-675-7481 \\ E-mail: gsbae@cau.ac.kr \\ ${ }^{1}$ Deparment of Animal Biosystem Sciences, Chungnam \\ National University, Daejeon 34134, Korea \\ 2 Department of Food Science \& Nutrition, Dongseo \\ University, Busan 47011, Korea \\ ${ }^{3}$ Department of Animal Science, Kyungpook National \\ University, Sangju 37224, Korea \\ ${ }^{4}$ Department of Agricultural Science, Korea National \\ Open University, Seoul 03087, Korea \\ ${ }^{5}$ Department of Animal Life and Environmental \\ Science, Hankyung National University, Anseong \\ 17579, Korea \\ ${ }^{6}$ Department of Animal Science and Technology, \\ Chung-Ang University, Anseong 17546, Korea \\ ORCID \\ Jong Nam Kim \\ https://orcid.org/0000-0002-8034-7156 \\ Jaeyong Song \\ https://orcid.org/0000-0002-8613-5605 \\ Eun Joong Kim \\ https://orcid.org/0000-0002-5962-6994 \\ Jongsoo Chang \\ https://orcid.org/0000-0003-4118-120X \\ Chang-Hyun Kim \\ https://orcid.org/0000-0001-6325-9755 \\ Seongwon Seo \\ https://orcid.org/0000-0002-4131-0545 \\ Moon Baek Chang \\ https://orcid.org/0000-0001-7872-5421 \\ Gui-Seck Bae \\ https://orcid.org/0000-0003-4006-1871
}

Submitted Jul 1, 2018; Revised Aug 11, 2018; Accepted Sept 10, 2018
Objective: Fasting may lead to changes in the microbiota and activity in the rumen. In the present study, the effects of fasting on rumen microbiota and the impact of fasting on in vitro rumen fermentation were evaluated using molecular culture-independent methods.

Methods: Three ruminally cannulated Holstein steers were fed rice straw and concentrates. The ruminal fluids were obtained from the same steers $2 \mathrm{~h}$ after the morning feeding (control) and $24 \mathrm{~h}$ after fasting (fasting). The ruminal fluid was filtrated through four layers of muslin, collected for a culture-independent microbial analysis, and used to determine the in vitro rumen fermentation characteristics. Total DNA was extracted from both control and fasting ruminal fluids. The rumen microbiota was assessed using denaturing gradient gel electrophoresis (DGGE) and quantitative polymerase chain reaction. Microbial activity was evaluated in control and fasting steers at various intervals using in vitro batch culture with rice straw and concentrate at a ratio of 60:40.

Results: Fasting for $24 \mathrm{~h}$ slightly affected the microbiota structure in the rumen as determined by DGGE. Additionally, several microorganisms, including Anaerovibrio lipolytica, Eubacterium ruminantium, Prevotella albensis, Prevotella ruminicola, and Ruminobacter amylophilus, decreased in number after fasting. In addition, using the ruminal fluid as the inoculum after $24 \mathrm{~h}$ of fasting, the fermentation characteristics differed from those obtained using non-fasted ruminal fluid. Compared with the control, the fasting showed higher total gas production, ammonia, and microbial protein production $(\mathrm{p}<0.05)$. No significant differences, however, was observed in $\mathrm{pH}$ and dry matter digestibility.

Conclusion: When in vitro techniques are used to evaluate feed, the use of the ruminal fluid from fasted animals should be used with caution.

Keywords: Holstein Steers; In vitro; Fasting; Rumen Microbiota; Denaturing Gradient Gel Electrophoresis

\section{INTRODUCTION}

In vitro feed evaluation using small tubes and ruminal fluid has been extensively used to examine ruminant diets in the academia and industry [1]. Such techniques are based on the ruminal fluid obtained from live animals equipped with permanent rumen cannulae and require several steps, including the removal of feed particles via muslin, cheesecloth, or centrifugation. Microbial activity is assumed to reach a peak after feeding; accordingly, numerous studies have examined the rumen contents collected post feeding [2-4]. However, some studies have noted that the ruminal fluid might mask the true effect of feed or feed additives if these effects are large. Therefore, the rumen contents are collected prior to feeding (i.e., before morning feeding) [5,6]. However, nutrient perturbation, even for short intervals, influences the rumen microbiota and microbial activity in the rumen [7]. In many countries where 
cannulated animals are seldom available owing to their maintenance costs, it is not uncommon for scientists to obtain the rumen contents only at an abattoir where the animals are fasted without feed and water for up to a day before they are slaughtered [8]. Therefore, one might speculate that the rumen contents obtained from animals after such short-term changes in status (i.e., fasting for a day) could affect the feed evaluation process. Unfortunately, little information is known about how the microbiome responds to short-term fasting. Fasting could cause microorganisms in the rumen to encounter decreased nutrients and habitat resources as well as increased competition for food. Therefore, fasting may lead to changes in the microbiota and activity in the rumen. The aim of the present study was to evaluate the potential effects of short-term starvation on rumen microbiota using in vivo molecular culture-independent methods as well as the effects on in vitro fermentation characteristics using the ruminal fluid obtained from animals that were fasted at least for $24 \mathrm{~h}$.

\section{MATERIALS AND METHODS}

This study was approved by the Institutional Animal Care and Use Committee at the Chung-Ang University, Seoul, Korea (No. 2013-0047).

\section{Animals and experimental design}

The representative rumen contents were obtained from three cannulated Holstein steers $(793 \pm 8 \mathrm{~kg}) 2 \mathrm{~h}$ after morning feeding (control). Then, fasting was induced by withdrawing both feed and water for $24 \mathrm{~h}$, and the rumen contents were obtained (fasting) from the same steers. The steers were offered typical commercial concentrates and rice straw at a ratio of 40:60. The rumen contents were filtrated through four layers of muslin, immediately sampled $(50 \mathrm{~mL})$, and snap-frozen for microbial analysis. Approximately $1 \mathrm{~L}$ of filtrated ruminal fluids was stored in individual Thermos bottles and transported to the laboratory for in vitro experiments.

\section{Isolation and purification of DNA}

For molecular microbial analyses, DNA was isolated from the ruminal fluid samples that were collected before (control) and after fasting (fasting) from steers using a previously described method [9]. Briefly, genomic DNA was extracted by bead-beating using a Mini Bead-beater (BioSpec Products, Bartlesville, OK, USA) for $4 \mathrm{~min}$ at full speed in the presence of $0.7 \mathrm{~g}$ of zirconium beads ( $0.1 \mathrm{~mm}$ in diameter), $282 \mu \mathrm{L}$ of Buffer $\mathrm{A}(0.2$ $\mathrm{M} \mathrm{NaCl}, 0.2 \mathrm{M}$ Tris, and $0.02 \mathrm{M}$ ethylenediaminetetraacetic acid [EDTA]; pH 8), $26.8 \mu \mathrm{L}$ of Buffer PM (QIAquick 96 PCR Purification Kit, Qiagen, Valencia, CA, USA), $200 \mu \mathrm{L}$ of $20 \%$ sodium dodecyl sulfate, and $550 \mu \mathrm{L}$ of a phenol-chloroformisoamyl alcohol mixture (25:24:1 by volume, $\mathrm{pH} 8)$. After centrifugation $\left(16,000 \times g\right.$ for $20 \mathrm{~min}$ at $\left.4^{\circ} \mathrm{C}\right)$, the supernatant was thoroughly mixed with $650 \mu \mathrm{L}$ of Buffer PB (Qiagen, USA), and the DNA sample was purified using the Qiagen PCR Purification Kit according to the manufacturer's protocol.

\section{Denaturing gradient gel electrophoresis analysis}

To perform denaturing gradient gel electrophoresis (DGGE) analysis, $16 \mathrm{~S}$ rRNA gene fragments of the $\mathrm{V} 3$ region were amplified using the primers GC-clamp-341f (5'-TCC TAC GGG AGG CAG CAG-5') and 518r (5'-ATT ACC GCC GCT GCT GG-3') as described previously $[10,11]$. Polymerase chain reaction (PCR) was performed using a TaKaRa Bio instrument (PCR Thermal Cycler, Otsu, Japan) in a final volume of $25 \mu \mathrm{L}$ with EmeraldAmp (GT PCR Master Mix, TaKaRa Bio, Japan), $1 \mu \mathrm{L}$ of each primer (GC-clamp 341f and GC-clamp 354r), 2 $\mathrm{U}$ of Taq polymerase (Ex Taq, TaKaRa Bio, Japan), and $1 \mu \mathrm{L}$ of template. After the initial denaturation at $94^{\circ} \mathrm{C}$ for $5 \mathrm{~min}$, amplification consisted of 30 cycles of denaturation (at $94^{\circ} \mathrm{C}$ for $30 \mathrm{~s}$ ), annealing (at $55^{\circ} \mathrm{C}$ for $30 \mathrm{~s}$ ), extension (at $72^{\circ} \mathrm{C}$ for $30 \mathrm{~s}$ ), and final extension step (at $72^{\circ} \mathrm{C}$ for $7 \mathrm{~min}$ ). The PCR product was checked using $2 \%$ agarose gel electrophoresis and visualized using a Gel Doc System (Bio-Rad, Hercules, CA, USA). PCR products were concentrated and purified using the QIAquick PCR Purification Kit (Qiagen, USA). The DGGE was conducted using the D-Code System (Bio-Rad, USA) with $8 \%(\mathrm{w} / \mathrm{v})$ polyacrylamide gels containing a $40 \%$ to $65 \%$ denaturant gradient, $1 \mathrm{~mm}$ thick, in $1 \times$ Tris acetate-EDTA buffer. Equal amounts of purified PCR products were loaded on the gel, and electrophoresis was performed at $25 \mathrm{~V}$ for $15 \mathrm{~min}$ and then $70 \mathrm{~V}$ for $16 \mathrm{~h}$ and $30 \mathrm{~min}$ at $60^{\circ} \mathrm{C}$. The gel was stained in $250 \mathrm{~mL}$ of running buffer containing ethidium bromide (50 $\mu \mathrm{g} / \mathrm{mL}$ ) for $15 \mathrm{~min}$. The stained gels were photographed under UV light using the Gel Doc XR documentation system (BioRad, USA). The normalization and analysis of gel profiles were conducted using the XLSTAT program (Addinsoft, New York, NY, USA).

\section{Quantitative polymerase chain reaction}

Populations of Fibrobacter succinogenes, Ruminococcus albus, Streptococcus bovis, Prevotella ruminicola, Prevotella albensis, Eubacterium ruminantium, Anaerovibrio lipolytica, Ruminococcus flavefaciens, methanogenic archaea, general protozoa, and general fungi were analyzed using a previously described quantitative PCR method [12-16]. Forty nanograms of extracted DNA was mixed with primers for the $16 \mathrm{~S}$ rDNA region of target bacteria or the ITS region of eukaryotic microbes and amplified using SYBR Premix Ex Taq (TaKaRa Bio, China) and the LightCycler 480 Real-Time PCR System (Roche, Mannheim, Germany). The PCR mixtures were pre-incubated at $95^{\circ} \mathrm{C}$ for $5 \mathrm{~min}$, denatured at $95^{\circ} \mathrm{C}$ for $10 \mathrm{~s}$, annealed at $58^{\circ} \mathrm{C}$ for $10 \mathrm{~s}$, and extended at $70^{\circ} \mathrm{C}$ for $10 \mathrm{~s}$. After 45 cycles of amplification, a melting point test was performed. The annealing temperatures for individual primers varied depending on the primer 
sequences. The PCR amplicon was inserted into the TOP10 competent cell (Invitrogen, Carlsbad, CA, USA). After DNA extraction, serially diluted DNAs were amplified to create a standard curve for the absolute quantification of individual microorganisms.

\section{In vitro batch culture experiment}

To investigate the effects of ruminal fluid on fermentation characteristics, two sets of in vitro experiments with the ruminal fluids obtained from steers were conducted. The substrates for the in vitro analysis were similar to the diets offered to the experimental steers, which received a mixture of $40 \%$ commercial concentrates and $60 \%$ rice straw. The concentrate and rice straw (Tables 1,2 ) were oven-dried at $60^{\circ} \mathrm{C}$ for 3 days, milled to pass through a 1-mm sieve, and analyzed for chemical composition using the appropriate AOAC [17] and Van Soest methods [18].

\section{Incubation conditions}

The medium [19] was dispensed into serum bottles under an-

Table 1. Ingredients of the concentrates (\% of dry matter) and composition (\% of dry matter) of concentrate and rice straw

\begin{tabular}{|c|c|c|}
\hline Items & Concentrate & Rice straw \\
\hline \multicolumn{3}{|l|}{ Ingredients } \\
\hline Ground corn & 3.02 & \\
\hline Wheat & 2.10 & \\
\hline Soybean meal & 2.40 & \\
\hline Rice bran & 1.00 & \\
\hline Tapioca & 17.8 & \\
\hline Sesame oil meal & 1.40 & \\
\hline Palm kernel meal & 41.08 & \\
\hline $\operatorname{DDGS}^{11}$ & 22.0 & \\
\hline Molasses & 5.00 & \\
\hline Condensed molasses soluble & 1.00 & \\
\hline Salt & 0.30 & \\
\hline Limestone & 2.00 & \\
\hline $\mathrm{CaCO}_{3}$ & 0.7 & \\
\hline Minerals and vitamins mixture ${ }^{2)}$ & 0.7 & \\
\hline \multicolumn{3}{|l|}{ Chemical composition } \\
\hline Dry matter & 88.27 & 87.83 \\
\hline Crude protein & 14.50 & 3.25 \\
\hline Ether extract & 6.77 & 1.54 \\
\hline Crude fiber & 12.68 & 28.40 \\
\hline Undegradable protein & 7.36 & - \\
\hline Ash & 7.49 & 15.68 \\
\hline Nitrogen-free extract & 47.10 & 38.74 \\
\hline Non-fiber carbohydrate & 19.83 & 1.66 \\
\hline Acid detergent fiber & 23.08 & 44.13 \\
\hline Neutral detergent fiber & 39.69 & 65.70 \\
\hline Total digestible nutrients & 71.02 & 38.29 \\
\hline
\end{tabular}

Table 2. Rumen fermentation parameters of experimental animals before and after fasting

\begin{tabular}{lcccc}
\hline Items & Control $^{1)}$ & Fasting $^{1)}$ & SEM & p-value \\
\hline $\mathrm{pH}$ & $5.88^{\mathrm{B}}$ & $6.27^{\mathrm{A}}$ & 0.0263 & 0.0005 \\
$\mathrm{NH}_{3}-\mathrm{N}(\mathrm{mg} / \mathrm{L})$ & $14.50^{\mathrm{B}}$ & $4.53^{\mathrm{A}}$ & 0.5807 & 0.0003 \\
Total volatile fatty acids (mmol/L) & $77.50^{\mathrm{B}}$ & $39.44^{\mathrm{A}}$ & 2.8125 & 0.0007
\end{tabular}

SEM, standard error of the mean.

1) Control, inoculum ( $2 \mathrm{~h}$ after feeding); Fasting, inoculum (fasting for $24 \mathrm{~h}$ ).

${ }^{A, B}$ Means in a row with different letters differ significantly $(p<0.05)$.

aerobic conditions [20]. It was then infused with $\mathrm{O}_{2}$-free $\mathrm{CO}_{2}$ gas, and, simultaneously, strained rumen fluid was added as a microbial suspension $(5 \%, \mathrm{v} / \mathrm{v})$ using a syringe. The serum bottles were crimped with butyl rubber stoppers with aluminum seals and then incubated at $39^{\circ} \mathrm{C}$ for $0,2,4,8,12$, and 24 $\mathrm{h}$ in a shaking water bath at $100 \mathrm{rpm}$. The experiments were performed in triplicate and conducted separately using the ruminal fluids obtained from each of three control and fasting animal. From each bottle, the gas volume was measured using a pressure detector (model PSGH-28PCCA, DECO Co., Seoul, Korea). Gas samples were collected in syringes with 3-way stopcocks from fermented gas-tight serum bottles, and $\mathrm{CO}_{2}$ and $\mathrm{CH}_{4}$ concentrations were estimated by gas chromatography (7890B GC, Agilent Technologies, Santa Clara, CA, USA). At the end of each incubation period, the supernatants were collected for $\mathrm{pH}$ determination and stored at $-20^{\circ} \mathrm{C}$ for analyses of $\mathrm{NH}_{3}-\mathrm{N}$ [21], volatile fatty acids (VFAs) [22], and microbial protein synthesis [23]. Dry matter digestibility was also determined by filtering residues in a filter crucible, drying at $100^{\circ} \mathrm{C}$, and weighing the resulting samples.

\section{Statistical analyses}

The rumen microbial fermentation characteristics, including $\mathrm{pH}$, gas production, $\mathrm{NH}_{3}-\mathrm{N}$, microbial protein, VFA, acetate: propionate ratio, and $\mathrm{CH}_{4}$ at $0,2,4,8,12$, and $24 \mathrm{~h}$, and the quantity of the rumen microbial DNA extracted from the rumen contents were analyzed statistically using the LSMEANS statement of the MIXED procedure in the SAS program package [24]. Statistical differences were determined at $\mathrm{p}<0.05$.

\section{RESULTS}

During fasting, steers did not show any abnormal symptoms until feed and water were reintroduced at the end of the study. The DGGE method was used to examine the differences in bacterial community between samples obtained before and after fasting (Figure 1). Although little variation was observed in fasting samples, we statistically compared the DGGE profiles of bacterial communities in control steers with those of each fasting steer. The variation and differences in community composition were analyzed by a clustering analysis of the DGGE gel profiles. Figure 1 shows that the DGGE profiles formed 


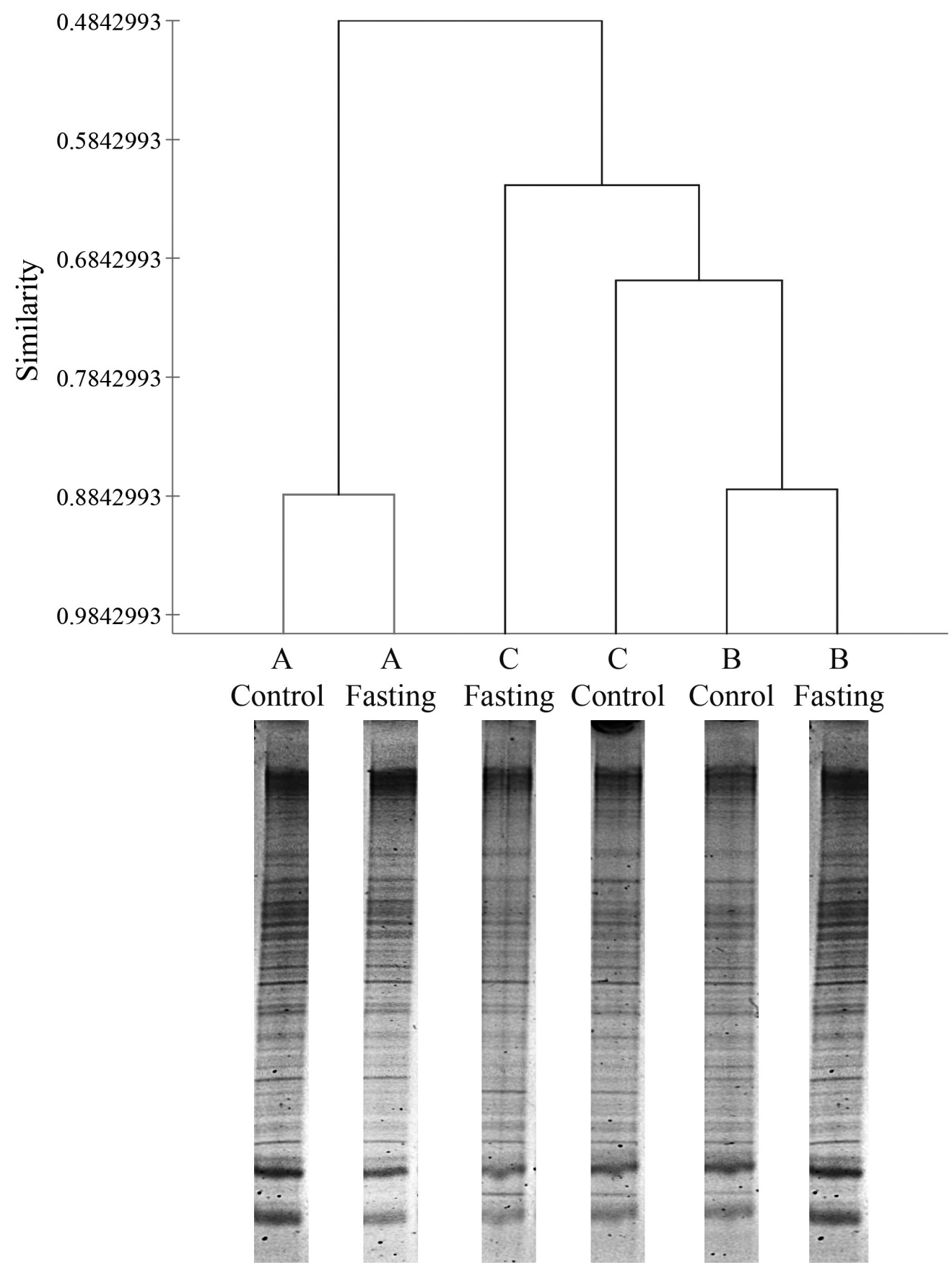

Figure 1. Effects of fasting on rumen microbiota based on the banding profile of denaturing gradient gel electrophoresis ( $A, B$, and $C$ indicate specific animals).

clusters representing each steer. The ruminal fluids of the control and fasted steers within treatments clustered together (steer A: $88.5 \%$ and steer B: $88.5 \%)$, except for steer C (67.6\%), and a variation was observed among steers, which suggests that the rumen bacterial community changes slightly with shortterm starvation (i.e., $24 \mathrm{~h}$ fasting). However, further analysis of the rumen microbiota showed marginal variation in the number of specific microorganisms (Table 3). The number of total bacteria (estimated as log copies) determined by qPCR was significantly $(\mathrm{p}<0.05)$ higher in the rumen contents of the control steers than in those of fasted steers. These differences reflect the differences between control and fasted steers in several specific rumen microorganisms, including Anaerovibrio lipolytica $(\mathrm{p}<0.05)$, Eubacterium ruminantium $(\mathrm{p}<0.05)$, Prevotella albensis $(\mathrm{p}<0.05)$, Prevotella ruminicola $(\mathrm{p}<0.05)$, and Ruminobacter amylophilus $(\mathrm{p}<0.05)$. However, the numbers of other major microorganisms in the rumen, such as protozoa, methanogenic archaea, and anaerobic fungi, did not differ between control and fasted animals (Table 3). Interestingly, substantial differences were found in the in vitro fermentation 
Table 3. The effects of fasting on the rumen microbiota based on real-time polymerase chain reaction

\begin{tabular}{|c|c|c|c|c|}
\hline \multirow{2}{*}{ Microorganisms } & Control $^{1)}$ & Fasting $^{1)}$ & \multirow{2}{*}{ SEM } & \multirow{2}{*}{ p-value } \\
\hline & \multicolumn{2}{|c|}{---- Log copies/ng ---- } & & \\
\hline Fibrobacter succinogenes & 8.03 & 8.05 & 0.045 & ns \\
\hline Ruminococcus albus & 5.85 & 5.48 & 0.012 & ns \\
\hline Ruminococcus flavefaciens & 3.83 & 3.72 & 0.078 & ns \\
\hline Anaerovibrio lipolytica & $3.32^{\mathrm{A}}$ & $3.02^{B}$ & 0.061 & 0.026 \\
\hline Eubacterium ruminantium & $4.24^{\mathrm{A}}$ & $4.05^{B}$ & 0.041 & 0.030 \\
\hline Prevotella albensis & $6.08^{A}$ & $5.89^{B}$ & 0.031 & 0.012 \\
\hline Prevotella ruminicola & $6.01^{\mathrm{A}}$ & $5.80^{B}$ & 0.045 & 0.027 \\
\hline Ruminobacter amylophilus & $5.83^{A}$ & $5.20^{B}$ & 0.117 & 0.020 \\
\hline Streptococcus bovis & 3.66 & 3.36 & 0.134 & ns \\
\hline Treponema bryantii & 6.61 & 3.57 & 0.047 & ns \\
\hline Total bacteria & $11.52^{A}$ & $11.31^{B}$ & 0.006 & 0.002 \\
\hline Protozoa & 4.73 & 4.75 & 0.104 & ns \\
\hline Methanogen & 3.97 & 4.08 & 0.082 & ns \\
\hline Fungi & 2.28 & 2.50 & 0.126 & ns \\
\hline
\end{tabular}

SEM, standard error of the mean; ns, not significant.

${ }^{1)}$ Control, inoculum ( $2 \mathrm{~h}$ after feeding); Fasting, inoculum (fasting for $24 \mathrm{~h}$ ).

$A, B$ Means in a row with different letters differ significantly $(p<0.05)$.

patterns when the rumen inoculum originated from control (no fasting) and fasted steers (Table 4). Although dry matter digestibility between control and fasted steers over the incubation period did not differ, total gas production, $\mathrm{CH}_{4}, \mathrm{CO}_{2}$, and VFA were higher $(\mathrm{p}<0.05)$ in the ruminal fluids of control animals than in the fluids from fasted animals throughout the incubation period.

\section{DISCUSSION}

The rumen microbiota changes according to various factors, including diet, time after feeding, ruminant species, and physiological status of the animal, among others [25]. Our results suggest that when animals are fasted for a short period of time (i.e., $24 \mathrm{~h}$ ), the rumen bacterial community changes slightly, but the number of total bacteria and specific populations differs between the rumen contents obtained before and after fasting. A previous study has shown that fasting impacts the gut microbiomes of tilapia, toads, geckos, quail, and mice [26]. According to the previous study, fasting induces changes in the microbiome in various host species and gut regions; however, microbial diversity increases with fasting in the colons of fish, toads, and mice. Presumably, this is explained by the limited nutrient supply in response to fasting, including water changes [27]. In addition, nutrient and water limitations may result in alterations in the relative abundance of ruminal microbes. This is interesting because large portions of ruminal microbes are solid-associated bacteria comprising $70 \%$ of the total bacteria in the rumen [7]. Therefore, when steers fast, even for just a short period (i.e., $24 \mathrm{~h}$ ), limited feed particles in the rumen are likely to reduce the number of solid-associ- ated bacteria. Indeed, the qPCR results in our study suggest that Prevotella and Ruminobacter decreased during fasting, whereas major cell wall-degrading bacteria ( $R$. albus, $R$. flavefaciens, and F. succinogenes) did not change. Presumably, this may be attributed to slower degradation and longer retention of fiber in the rumen; cellulose-degrading bacteria could maintain their niches for longer than other bacteria. According to compartment theory, rumen microbes are classified by their distance from the feed particles or rumen epithelial tissue [7].

The planktonic bacterium Prevotella and weakly particle attached bacterium Ruminobacter are classified as compartment 1 and 2, respectively. The viability of those bacteria are more sensitive to the existence of available substrate than the other compartments which are tightly bind to substrate or rumen epithelial tissue. The decreased amounts of accessible substrates in the rumen caused decrease in the populations of planktonic and weakly particle attached bacteria during short-term fasting.

The objective of the present study was to examine the effect of fasting on rumen microbiota. Many laboratories worldwide use ruminal fluids as the microbial inoculum for in vitro fermentation studies, and differences in the rumen content properties may explain the differences in study outcomes. This concern is particularly important when comprehensive approaches, such as meta-analyses, are used for in vitro gas production and/or digestibility studies. Indeed, a recent metaanalysis of in vitro techniques indicated issues with these techniques for measuring gas and methane production and suggested "greater harmonization of analytical procedure" to improve our understanding of the results $[28,29]$. A previous study by Johnson [1] indicated the importance of the rumen inoculum from animals offered different forages when examining forage digestion in vitro, and more recently, excellent reviews have highlighted the critical requirements for in vitro studies [3]. According to Payne et al [4], gas production profiles are less variable at 4 or $8 \mathrm{~h}$ post-feeding than those either just before or $2 \mathrm{~h}$ post-feeding. This is in contrast with the findings of Menke and Steingass [6].

Our results suggest that the use of the ruminal fluid from fasting animals should be interpreted with caution. Although such findings do not preclude the use of the ruminal fluid from a slaughterhouse, additional care may be imperative, especially when comparisons are attempted among in vitro analyses. Extensive variation among animals was observed, and hence the use of single animals for in vitro or even in situ techniques may be suboptimal.

\section{CONFLICT OF INTEREST}

We certify that there is no conflict of interest with any financial organization regarding the material discussed in the manuscript. 
Table 4. Rumen fermentation characteristics determined using the rumen inoculum of non-fasted (control) and fasted (fasting) steers in vitro

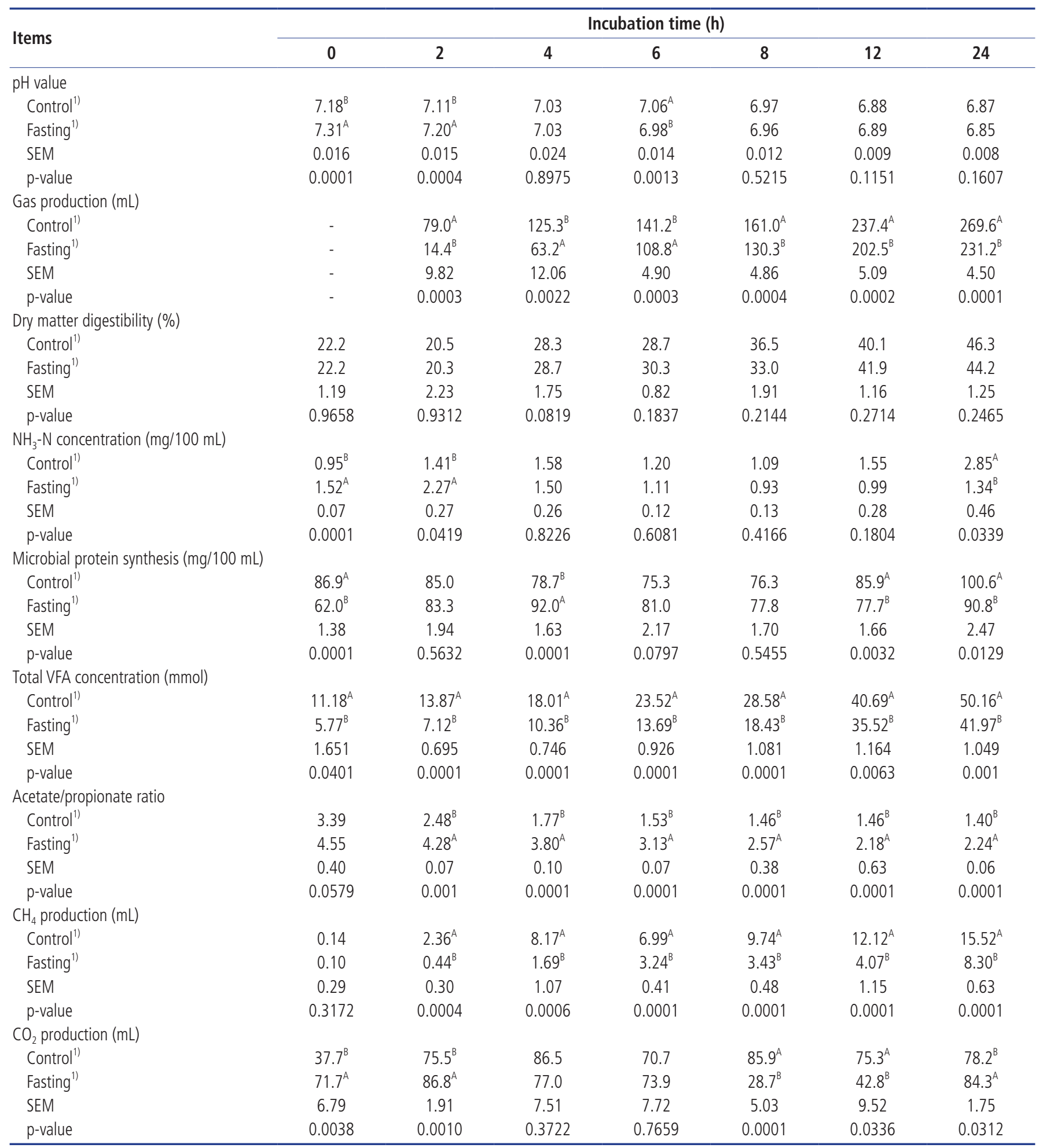

SEM, standard error of the mean; VFA, volatile fatty acids.

1) Control, inoculum ( $2 \mathrm{~h}$ after feeding); Fasting, inoculum (fasting for $24 \mathrm{~h}$ ).

$A, B$ Means in a column with different letters differ significantly $(p<0.05)$.

\section{ACKNOWLEDGMENTS}

This work was supported by the Korea Institute of Planning and Evaluation for Technology in Food, Agriculture, Forestry (IPET) through the Agri-Bio industry Technology Development Program, funded by the Ministry for Agriculture, Food 
and Rural Affairs (MAFRA) (118073-03). We are also grateful to the EasyBio Co. Ltd. for their support for this study.

\section{REFERENCES}

1. Johnson RR. Techniques and procedures for in vitro and in vivo rumen studies. J Anim Sci 1966;25:855-75.

2. Kim DH, Amanullah SM, Lee HJ, et al. Effects of different cutting height on nutritional quality of whole crop barley silage and feed value on Hanwoo heifers. Asian-Australas J Anim Sci 2016; 29:1265-72.

3. Mould FL, Kliem KE, Morgan R, Mauricio RM. In vitro microbial inoculum: a review of its function and properties. Anim Feed Sci Technol 2005;123-124, Part 1:31-50.

4. Payne JS, Hamersley AR, Milligan JC, Huntington JA. The effect of rumen fluid collection time on its fermentative capacity and the stability of rumen conditions in sheep fed a constant diet. In: Proceedings of the British Society of Animal Science, UK: British Society of Animal Science; 2002. p. 165.

5. Jeon S, Sohn K-N, Seo S. Evaluation of feed value of a byproduct of pickled radish for ruminants: analyses of nutrient composition, storage stability, and in vitro ruminal fermentation. J Anim Sci Technol 2016;58:34.

6. Menke KH, Steingass $\mathrm{H}$. Estimation of the energetic feed value obtained from chemical analysis and in vitro gas production using rumen fluid. Anim Res Dev 1988;28:7-55.

7. McAllister TA, Bae HD, Jones GA, Cheng KJ. Microbial attachment and feed digestion in the rumen. J Anim Sci 1994;72: 3004-18.

8. Chaudhry AS, Mohamed RAI. Fresh or frozen rumen contents from slaughtered cattle to estimate in vitro degradation of two contrasting feeds. Czech J Anim Sci 2012;57:265-73.

9. Rius AG, Kittelmann S, Macdonald KA, et al. Nitrogen metabolism and rumen microbial enumeration in lactating cows with divergent residual feed intake fed high-digestibility pasture. J Dairy Sci 2012;95:5024-34.

10. Ben Omar N, Ampe F. Microbial community dynamics during production of the Mexican fermented maize dough pozol. Appl Environ Microbiol 2000;66:3664-73.

11.Yu Z, Morrison M. Comparisons of different hypervariable regions of rrs genes for use in fingerprinting of microbial communities by PCR-denaturing gradient gel electrophoresis. Appl Environ Microbiol 2004;70:4800-6.

12.Lopez I, Ruiz-Larrea F, Cocolin L, et al. Design and evaluation of PCR primers for analysis of bacterial populations in wine by denaturing gradient gel electrophoresis. Appl Environ Microbiol 2003;69:6801-7.

13. Fernando SC, Purvis II HT, Najar FZ, et al. Rumen microbial population dynamics during adaptation to a high-grain diet. Appl Environ Microbiol 2010;76:7482-90.

14. Karnati SK, Yu Z, Sylvester JT, et al. Technical note: Specific
PCR amplification of protozoal 18S rDNA sequences from DNA extracted from ruminal samples of cows. J Anim Sci 2003;81:812-5.

15. Koike S, Kobayashi Y. Development and use of competitive PCR assays for the rumen cellulolytic bacteria: Fibrobacter succinogenes, Ruminococcus albus and Ruminococcus flavefaciens. FEMS Microbiol Lett 2001;204:361-6.

16. Shin EC, Choi BR, Lim WJ, et al. Phylogenetic analysis of archaea in three fractions of cow rumen based on the $16 \mathrm{~S}$ rDNA sequence. Anaerobe 2004;10:313-9.

17.AOAC. Official methods of analysis (16th Ed.). Washington, DC, USA: Association of Official Analytical Chemists; 1995.

18. Van Soest PJ, Robertson JB, Lewis BA. Methods for dietary fiber, neutral detergent fiber, and nonstartch polysaccharides in relation to animal nutrition. J Dairy Sci 1991;74:3583-97.

19. McDougall EI. Studies on ruminant saliva. 1. The composition and output of sheep's saliva. Biochem J 1948;43:99-109.

20. Miller TL, Wolin MJ. A serum bottle modification of the Hungate technique for cultivating obligate anaerobes. Appl Microbiol 1974;27:985-7.

21. Chaney AL, Marbach EP. Modified reagents for determination of urea and ammonia. Clin Chem 1962;8:130-2.

22. Erwin ES, Marco GJ, Emery EM. Volatile fatty acid analyses of blood and rumen fluid by gas chromatography. J Dairy Sci 1961;44:1768-71.

23.Lowry OH, Rosebrough NJ, Farr AL, Randall RJ. Protein measurement with the Folin phenol reagent. J Biol Chem 1951;193: 265-75.

24.SAS. SAS Procedures Guide, Version 8. Cary, NC, USA: SAS Institute Inc.; 1999.

25. Carberry CA, Kenny DA, Han S, McCabe MS, Waters SM. Effect of phenotypic residual feed intake and dietary forage content on the rumen microbial community of beef cattle. Appl Environ Microbiol 2012;78:4949-58.

26. Kohl KD, Amaya J, Passement CA, Dearing MD, McCue MD. Unique and shared responses of the gut microbiota to prolonged fasting: a comparative study across five classes of vertebrate hosts. FEMS Microbiol Ecol 2014;90:883-94.

27. McCue MD. An introduction to fasting, starvation, and food limitation. In: McCue MD, editor. Comparative physiology of fasting, starvation, and food limitation. 1 ed: Berlin Heidelberg, Germany: Springer-Verlag; 2012. p. 1-5.

28. Maccarana L, Cattani M, Tagliapietra F, et al. Methodological factors affecting gas and methane production during in vitro rumen fermentation evaluated by meta-analysis approach. J Anim Sci Biotechnol 2016;7:35.

29. Lee SJ, Shin NH, Jeong JS, et al. Effects of Gelidium amansii extracts on in vitro ruminal fermentation characteristics, methanogenesis, and microbial populations. Asian-Australas J Anim Sci 2018;31:71-9. 